\title{
DEVELOPING EFFECTIVE UNDERGRADUATE ONLINE HISTORY COURSES: AN EXPERIENTIAL MODEL
}

\author{
Michael E. Brooks \\ Bowling Green State University
}

\section{Introduction}

This article offers an overview of the techniques and strategies that I have found most successful in a ten-year career teaching undergraduate history courses in online and hybrid settings. While geared toward instructors new to online teaching, veteran online instructors should also find useful ideas here to improve their virtual classrooms.

Instructors seeking to hone online teaching skills should take advantage from the onset of as many formal training opportunities as possible. A University of Central Florida study noted that faculty members who have taken part in online pedagogy seminars experienced renewed interest in teaching as a result of their participation in online trainings. ${ }^{8}$ It is critical to stay current with the rapidly evolving world of educational technology, and the best way to accomplish this is to interact regularly with other online instructors and designers. Most colleges and universities offer internal training for their current learning management system (LMS), while the creators of the LMS platform typically provide online question-and-answer forums for users.

Seminars and trainings offered by Quality Matters ${ }^{9}$ and the Sloan-CConsortium ${ }^{10}$ are excellent venues to develop online teaching skills and network with other online teaching professionals. Quality Matters also has designed a nationally-recognized peer review process and rubric that certifies the quality of online classes.

\section{Developing an Online Teaching Philosophy}

Before beginning to teach history online, instructors should develop a separate philosophy of teaching for online courses. Certainly there is considerable overlap in both types of classrooms (traditional and online), but many new online instructors make the mistake of attempting simply to duplicate their face-to-face (F2F) classes online rather than creating wholly new online learning environments.

An important component of an online teaching philosophy is instructor willingness to wear additional institutional hats. As much as possible, online instructors

\footnotetext{
${ }^{8}$ University of Central Florida, "Research Initiative for Teaching Effectiveness: Faculty Perceptions of Teaching on the Web," http://online.ucf.edu/research/dl-impact-evaluation/\#Perceptions (accessed September 2, 2015).
}

${ }^{9}$ Quality Matters, https://www.qualitymatters.org/ (accessed September 2, 2015).

${ }^{10}$ Sloan-C Consortium, http://slsoanconsortium.org/ (accessed September 2, 2015). 
need to be technological problem-solvers for students. Admittedly it might be easier to send a student with a question regarding the LMS to tech support personnel. However, if instructors can answer student questions adequately on their own, problem resolution is much faster. Moreover, student engagement and retention increase when instructors take time to troubleshoot basic technological problems, and given the lower rates of student retention in online settings, ${ }^{11}$ efforts by front-line instructors of online classes are crucial in maximizing student retention.

Most technological problems faced by students fall into one of the following categories:

- Browser compatibility issues with the online platform;

- Difficulty in understanding solutions to word processor programs;

- Software compatibility issues (such as between MS-Word and the LMS). One need not be a high-tech savant in order to be helpful to students who face technological problems in an online classroom. Solutions to student technical problems often can be found by using a search engine such as Google to find help forums for the LMS. If a problem occurs for which the instructor has no solution, instructors at least can follow up with students to ensure that tech support has solved the problem. At a minimum, instructors need to provide links in their syllabi and course shells (another term for the individual course website) to help resources.

Consistent student outreach is another significant component of an online teaching philosophy. Unlike F2F classes, where students interact in a physical classroom with the instructor, online students (especially students new to online settings) sometimes feel alienated. ${ }^{12}$ Most online platforms offer diagnostic tools to help instructors quickly identify struggling or non-participatory students, such as analytical data or site visit history, and a simple telephone call or email can be effective in getting such students back on track before they fall too far behind. ${ }^{13}$ Reducing the

\footnotetext{
${ }^{11}$ Retention rates might be as much as twenty percent lower in online classes than in F2F classes, although some of this could be due to the fact that online environments are more likely to attract "exploratory" students than brick-and-mortar institutions. See Wallace E. Boston, et al., "Comprehensive Assessment of Student Retention in Online Learning Environments," Online Journal of Distance Learning Administration, IV (Spring 2011), http://www.westga.edu/ distance/ojdla/spring141/ boston_ice_gibson 141.html (accessed September 2, 2015).
}

${ }^{12}$ Alfred P. Rovait and Mervyn J. Wighting, "Feelings of Alienation and Community among Higher Education Students in a Virtual Classroom," Internet and Higher Education, 8 (2005), 97-110.

${ }^{13}$ The most significant factor in predicting the likelihood of withdrawal from an online class is class rank: Seniors are less likely to withdraw from online courses than non-seniors, while withdrawal rates are highest for freshmen. See Justin D. Cochran, et al., "The Role of Student Characteristics in Predicting Retention in Online Courses," Research in Higher Education, 55 (2014), 42. 
"disappearing student" phenomenon is especially critical in the early weeks of a semester, when early alert systems can be most effective. ${ }^{14}$

Creating an interactive learning environment is another critical component of an online teaching philosophy. In addition to the instructor's individual and group interactions with online students, it is important to develop opportunities for students to interact with peers via group projects and discussion forums. This is one way to break the isolation that some might experience in an online course that lacks the interaction of $\mathrm{F} 2 \mathrm{~F}$ settings.

\section{Before the Course Begins}

In online classes it is important to be more proactive than in $\mathrm{F} 2 \mathrm{~F}$ classes about getting important course information to students, as some students enrolled in online courses might be located in places far from the physical location of the institution. These distances represent logistical challenges, especially in obtaining textbooks and other course materials.

Syllabi for online history courses should contain a number of components that are different from those created for F2F classes. In addition to sections related to technological items, syllabi for online courses need to contain specific information related to the virtual classroom experience. This would include (but is not limited to) details such as the preferred method of contacting the instructor, assignment submission instructions, acceptable file formats for papers, and a discussion of the differences for students between online and F2F classes.

Email the syllabus to students a week in advance and send out a separate email with the required texts for the course at the same time. This method counters the normal level of student procrastination and/or delays in obtaining financial aid associated with acquiring textbooks. In the emails stress that students will begin using the textbooks the very first day of class in order to emphasize the importance of prompt acquisition of course materials.

Consider opening course shells at least three days before the term begins so that students will have time to surf the website, learn the course layout, and familiarize themselves with course expectations. On average, about half the students take advantage of the early opening to visit the website, and approximately one-fourth on average actually begin work in the class. Sometimes this takes the form of watching course videos, while other times students actually complete assignments from the first week before the official start date. Some universities control student access to course

\footnotetext{
${ }^{14}$ The most significant challenge with early alert systems is getting buy-in from stakeholders. Until the "messy, human side of educational technology" changes, early alert systems will not be a silver bullet solution. See Melinda Mechur Karp, "Tech Alone Won't Cut It," Inside Higher Ed, January 13, 2014, http://www.insidehighered.com/views/2014/01/13/essay-looks-how-early-warning-systems-can-betterboost-retention (accessed September 2, 2015).
} 
shells via preset, system-wide open and close dates, but most online leaming platforms allow individual instructors to choose the start and end dates for a course.

The use of a brief syllabus quiz helps reinforce course policies and expectations. The quiz can be weighted as little as twenty points for a 1000 -point course. It should cover items that generally had been sources of confusion to students (and occasionally sources of aggravation to the instructor). Consider the use of quiz questions as opportunities for interactivity and learning. Include feedback with quiz questions, explaining the correct answer so that students learn from the incorrect answer. Below is a response to students who incorrectly answered a syllabus quiz question on the number of required discussion board responses:

Commenting on at least two other essays is a requirement, and the failure to do so will result in lower discussion grades. Discussion forums create the online equivalent of scholarly classroom conversations, and the interaction with other students is a critical part of the learning process in this course. In many discussion forums there are lengthy conversations occurring between students that take on lives of their own. ${ }^{15}$

During the early opening of the course shell, many students complete what I consider to be an important interactive component of the course, a forum entitled "Introduce Yourself." In this required forum, students post an autobiographical essay and respond to the essays of other students according to a detailed prompt.

This personal essay and related student responses work well as ice-breakers, which is an ideal way for an instructor to make connections with students at the start of the semester. The instructor should respond to each student introduction in a fairly lengthy manner, typically at least 100 words. I try to identify at least two items I have in common with each student in an effort to cement interpersonal relationships between the students and myself. One study noted that the first days of an online course are "a critical time for establishing instructor presence," and that "in the absence of a physical instructor, students look to whatever text and image-based presence might be available to learn more about" the person leading the course. ${ }^{16}$ Making these early connections reduces student alienation, increases student participation, and lowers the likelihood that students will find an online instructor to be unapproachable. Instructors might find this forum to be exciting: They can learn about the students taking online classes in a more detailed way than in the first week of F2F classes, and students are more likely

\footnotetext{
${ }^{15}$ Michael E. Brooks, "Converting a Narrated PowerPoint into a WMV Video," https://www.youtube.com/watch?v=IRA2cH7izU4 (accessed August 13, 2013).

${ }^{16}$ Vanessa Paz Dennen, "Presence and Positioning as Components of Online Instructor Persona," Journal of Research on Technology in Education, 40:1 (2007), 96.
} 
to offer insights into their goals and dreams in an online forum than they would in a first-day F2F icebreaking exercise.

\section{Course Shell Design}

As a rule, make course shells as easy to navigate as is possible. The first step in this process is to limit the number of items on the navigation bar. ${ }^{17}$ Students-especially individuals new to online learning — can become overwhelmed if confronted with a wide array of navigational tabs. One can effectively cover pedagogical needs--while maintaining simplicity of design-with about six navigational tabs. ${ }^{18}$

Create a page in the course shell that is titled "Start Here," and provide several links to this page in places where students first visit, such as in the announcements section, in the course modules, and in the syllabus. The "Start Here" page includes a truncated overview of key syllabus items and details the first steps students should take as they begin the course. Include a list of minimum technological requirements student computers need as well as a brief discussion about "Netiquette," reiterating expectations about social interaction in the course syllabus. Interestingly, research indicates that students as well as instructors share this need for clear Netiquette expectations. ${ }^{19}$ Students want to work in an environment relatively free from the more abrasive features of many online environments.

Create redundancy in online courses through frequent use of hyperlinks to reference important items. For example, any time in the course shell the word "syllabus" is mentioned, hyperlink that term with the syllabus page or file. Make use of links in comments to students in discussion forums or in grading feedback through what the author refers to as "individualized hyperlinked instruction," whereby instructors hyperlink to external sources any terms unfamiliar to students as well as content-related material that expands the knowledge base.

\footnotetext{
${ }^{17}$ Most learning management systems include some sort of sidebar with tabs to important course functions. Blackboard, for example, allows instructors and instructional designers to customize these under the "Manage Course Menu" function. Canvas has standardized menu tabs with common functions, but customization of the names of the tabs is not offered as an option. Sakai and Moodle allow greater customization.
}

\footnotetext{
${ }^{18}$ Rob Kelly, editor, "Online Course Design: 13 Strategies for Teaching in a Web-based Distance Learning Environment," Online Classroom, http://hilo.hawaii.edu/academics/d1/documents/ 13StrategiesforTeaching.pdf (accessed September 2, 2015).
}

\footnotetext{
${ }^{19}$ Myrna J. Dow, "Implications of Social Presence for Online Learning: A Case Study of MLS Students," Journal of Education for Library and Information Sciences, 49:4 (Fall 2008), 231-242.
} 
In my own teaching, I have migrated toward a module-based approach to organizing course materials and assignments over the past few years. Modules follow a chronological approach based on semester weeks, and each module incorporates weekly themes based on the historical content for each week toward which lectures and assignments are oriented.

In designing an online undergraduate history course, I emphasize student writing. Student essays and projects typically comprise 50-65 percent of the total course grade in my survey-level classes. The higher weight given to writing assignments reflects my observations and experiences that writing essays and doing research projects provide better assessments in gauging student comprehension and student mastery of course learning outcomes. Using 1000 points as the basis for classes helps students easily understand grades at any moment in the term.

Multiple choice and true-false questions constitute a relatively small portion of the overall grade in my courses. Quizzes and exams are the only components in which lower-order assessments such as multiple choice and true-false questions might appear. Typically the vast majority of the components of the grades in my undergraduate courses are determined by scores on essay-based exams, research papers, discussion forum essays, and other written projects.

\section{Discussion Forums}

Discussion forums are a critical piece in designing a course that is capable of enhancing deeper learning. Some of the most impressive student work comes from the reflective and interactive components of a discussion forum, mirroring findings from Susan Land and Michele Dornisch that "students progressively deepened their understanding, as they clarified ideas, asked questions, and refined their initial conceptions" through the use of discussion forum assignments. ${ }^{20}$ At the beginning of the course, I spend extra time educating students about the importance of forums and expectations regarding the quality of work and participation. The inclusion of discussion guidelines in the syllabus and on the course website reduces the number of problems that can occur with students who are unfamiliar with the expectations of academic discourse (or who spend a great deal of time on free-for-all Internet sites where personal attacks are the norm).

Instructors new to the online classroom might feel a compulsion to provide a written response to every initial post by every student on each discussion forum. However, this is not a realistic expectation, as one class of 25 students would generate 400 initial posts in a sixteen-week term, and an instructor who attempted to post even

\footnotetext{
${ }^{20}$ Susan Land and Michele Dornisch, "A Case Study of Student Use of Asynchronous Bulletin Board Systems (BBS) to Support Reflection and Evaluation," Journal of Educational Technology Systems, 30:4 (2002), 375.
} 
as little as 100 words in response to every post would write the equivalent of a 40,000 word monograph over the course of a single semester.

Instead, in a class of 25 students, a half-dozen quality comments per week is a much more reasonable objective, and responding to a variety of different students each week means that each student will receive in-depth comments on several discussion forum essays over the semester. Comments earlier in the week set the tone for the discussion and make the instructor's presence known. Interestingly, research suggests that too much instructor presence in discussion forums might be as deleterious as too little presence, as instructors who insert their subject matter expertise into discussion might actually inhibit peer interaction. ${ }^{21}$

In grading discussion forums, I assign eighty percent of the grade to the quality of the initial post, which takes the form of a 400-600 word essay. The remaining twenty percent of the discussion forum grade is based on the quality and quantity of comments provided to other students, and students receive a grading rubric with each discussion forum. I require a minimum of two "meaningful" 22 comments per forum from each student, and hypothetical examples of high-quality and low-quality responses can be found in the syllabus. I was a bit idealistic when first teaching online, thinking I would not require responses but instead encourage responses by creating such engaging forums that there would be excellent participation organically. However, many students would not produce any extra effort if there were no points associated with the activity, and the comments that did appear were almost exclusively the highly motivated A students.

In discussion forum prompts, I build in a variety of different types of activities, including such activities as: a) primary source comparison/analysis; b) interpretations of historical artwork; and c) essays in which students imagine themselves to be living in the time period being studied in the module. It is important to design forum assignments in which text cannot be simply copied-and-pasted from the Internet. Here is an example of a discussion prompt from a survey-level world history course that illustrates the third type of prompt:

For this week's essay imagine that you are a person living in one of the regions and time periods covered in the texts this term. Begin your first-

\footnotetext{
${ }^{21}$ Vanessa Paz Dennen, "From Message Posting to Learning Dialogues: Factors Affecting Learner Participation in Asynchronous Discussion," Distance Education, 26:1 (2005), 127-148. See also Timothy Barnett-Queen, Robert Blair, and Melissa Merrick, "Student Perspectives of Online Discussions: Strengths and Weaknesses," Journal of Technology in Human Service, 23:3/4 (2005), 229-244.

22" Meaningful" is defined for the students in a detailed description in the syllabus and on the grading rubric. In short, students are expected to engage in substantive dialogue with the original poster as opposed to disengaged statements such as "good job" or "nice work."
} 
person narrative by briefly describing such items as your daily life and family situation. Next, discuss the social, economic, and political changes that are occurring around you. What are the most important issues you face? To what extent do you control your own destiny, and to what extent is your life largely driven by forces you cannot control? Why does your character think this way? What forces or people exercise control over your character? Stronger essays will reflect evidence that the student has mastered the information in the course textbooks, lectures, and supplemental materials. ${ }^{23}$

This sort of activity typically would be used near the end of the term as a means to assess the mastery of learning objectives. This type of ruminative essay is also useful for students as they prepare for final examinations.

\section{Video Lectures}

When I first started, I provided Microsoft PowerPoint presentations for topic lectures in online undergraduate courses. Over time, though, I became frustrated with the amount of time spent providing technical support to students. Problems included students having outdated versions of PowerPoint, students who did not use PowerPoint or who lacked access to the software, and students for whom PowerPoint was simply a struggle. Instead I developed a seamless and easy-to-access method of delivering lectures, using narrated PowerPoints converted to WMV videos that could then be hosted on YouTube. ${ }^{24}$

The benefits of this approach are numerous, especially being freed up from providing technical assistance to students for whom PowerPoint was problematic. Students simply click the hyperlink and instantaneously access course lectures, and, more importantly, students with smart phones can watch lectures almost any time they want if they have Wi-Fi access. Even better, with the Canvas LMS, simply pasting the URL on a course page converts the URL to an embedded YouTube player. Of course, compared to some disciplines, history lends itself well to narrated videos, and there never seems to be a shortage of relevant and engaging topics that can be added to a video to liven up the presentation, such as a brief discussion of Rasputin in a Bolshevik Revolution video or the bombing of Guernica in a Spanish Civil War video.

\footnotetext{
${ }^{23}$ Brooks, 2013.
}

\footnotetext{
${ }^{24}$ The following link connects to a video that explains the production process; readers can access the video via YouTube: https://www.youtube.com/watch?v=IRA2cH7izU4 (accessed September 2, 2015).
} 
The optimal time for video lectures is the three-to-five minute range, with a general pedagogical goal of keeping all videos under ten minutes. ${ }^{25}$ It is better to have a series of shorter videos than one long video, as students are more likely to access short videos. Timing in video lectures is different than with traditional lectures, as an hour of F2F lecture ends up being 5-8 minutes of video if the instructor develops a detailed script. This is due to the faster pace of video lectures, which are more like news reports or documentaries than traditional lectures. In addition, the process of condensing content to a short video also reflects the lack of class discussion or students asking the instructor to slow down during a traditional F2F lecture.

Some educators are reluctant to create video lectures for fear that the finished product will not be of high quality. While it is true that one's initial attempts to develop video lectures might not be perfect, and even amateurish, the only way to develop this skill is simply to jump in and experiment, avoiding obsessing over perfection, as we are educators, not Hollywood directors. Minor glitches will not mar an otherwise strong lecture, nor will students even notice most technical shortcomings. Besides, editing these lectures is quite simple, and one need not re-record an entire lecture because one small segment happens to be clunky.

Make video lectures seems as "live" as possible. The best way to accomplish this goal is to include video footage of the instructor as part of the lecture. Include at least some introductory footage of the instructor in video lectures and one other "live" segment, even just a ten-second transition. When possible, add a "live" conclusion to video lectures with a brief summary of the topics covered in the lecture.

In the most effective style of video lectures, the instructor maintains a relatively informal and personal style of narration. Look directly into the camera in these segments, which is in keeping with current pedagogical best practices, ${ }^{26}$ and use the traditional newscaster approach of looking down for a few seconds at notes before returning right back to face the camera. The addition of personal experiences and life anecdotes helps liven up video lectures, and they help students make connections across temporal and geographical divides. A dose of humor also can be effective in illustrating points, but be careful: Sometimes humor does not translate well across cultures, and humor works best in segments where students can see the instructor's face on the screen to pick up visual clues.

When narrating a video lecture or creating a "live" segment, be sure to speak clearly, to enunciate, and to speak with confidence. It might take a few practice recordings to develop a confident delivery, so do not be disappointed if the first take of the first video comes across as less-than-polished. Even a choppy video lecture is

\footnotetext{
${ }^{25} J a n e t$ Whatley and Amrey Ahmad, "Using Video to Record Summary Lectures to Aid Students' Revision," Interdisciplinary Journal of Knowledge and Learning Objects, 3 (2007), 187.
}

${ }^{26}$ Whatley and Ahmad, 193. 
more effective at delivering content and helping students understand concepts than a completely static textual passage or non-narrated PowerPoint lecture. Remain as timeless as possible: Narrators of video lectures should avoid referencing specific contemporary events or popular culture, as these items can make the lecture seem outdated quickly, necessitating editing or even a complete revision of the video lecture. Finally, be sure to use detailed scripts: Even if you are a polished speaker, the use of scripts reduces the "umm" and "uh" factor, leading to a more polished production. Scripts also reduce the amount of time you spend on videos, since you are more likely to include everything you wanted to cover, and the net result is a tighter and professional production.

There are a few technical recommendations to keep in mind as you plan the production of video lectures. Using the method outlined in the video tutorial (see footnote 8) an instructor does not need a technical assistant, but a work-study student or teaching assistant is a logical choice for delegation. Either way, make sure to test the recording environment. Be sure to run lighting and sound checks before recording, as nothing is more frustrating than creating a video only to find out the microphone was off or the lighting was too dim. Use the best hardware that you can afford: Most laptops have built-in cameras and microphones, but the sound and video quality of these free tools is somewhat low. Inexpensive external webcams and microphones will produce much better videos. Finally, be sure to proof videos before releasing them in a live environment to avoid any glaring errors from becoming viral memes in social media.

Many programs are available for instructors to use to produce high-quality video lectures. Some are free, and some can be purchased; be sure to check around your institution to see what software already is available. Camtasia Studio is an excellent tool for PC users, while ScreenFlow works well in Mac environments. Screencast-oMatic is also popular, and this software is available in PC and Mac versions.

Keep the pace lively in the video lecture, and limit time on individual slides to thirty seconds or less. A pace of at least three narrated slides per minute makes the video seem more like a documentary. Avoid the use of gimmicks such as text animations, unnecessary sound effects, or silly fonts, all of which can be distractive to students viewing the lecture. Emphasize images over text on the individual slides, as the screen focus in video lectures should be on images, keeping text to a minimum, such as a title and just a few important terms. Try to keep at least eighty percent of the screen as a single image with a brief headline across the top plus a few relevant terms. Be aware of academic jargon and foreign terms that might confuse students, and be sure to spell out words students might not know, or use video-editing to insert a quick caption for unfamiliar words. Finally, include the lecture material as the basis for quizzes and exams: If students do not see a direct connection between the material and their course grades, they are much less likely to access the video lectures. 


\section{Quiz, Exam, Discussion, and Assignment Design}

When designing any assessment or assignment for an online history course, it is important to keep in mind that online students generally have access to course texts and Internet browsers. ${ }^{27}$ One group of educators suggests that the changing nature of information retrieval and ubiquitous access to information means that we should be reinventing the entire process of education. Instead of cracking down on online students as somehow "cheating," we might simply allow our F2F students the same opportunity to use study aids during exams. Such behavior, as goes the argument, more closely mirrors the employment world that today's graduates will face, as it is almost unthinkable that a person would have to memorize prodigious amounts of content to be successful in a career. This approach could be described as an open-note, open-book, and open-browser methodology, and a number of studies suggest little difference in achievement between open- and closed-source environments. ${ }^{28}$

Anecdotally I have experimented with open-note and open-book exams in several F2F classes. There did not appear any statistically meaningful difference in these classes than from exam results traditionally found on closed-book, no-notes exams. One of the keys, though, is to design exams and quizzes with questions that cannot be answered easily by a quick Google search and jumping to the index of a textbook.

Place time limits on quizzes with multiple choice or true-false questions, capping the time at sixty to ninety seconds per question. ${ }^{29}$ This reduces what Thomas Brothen and Catherine Wambach have called the "quiz-to-learn" approach, ${ }^{30}$ whereby students only open the textbooks as they go along during a quiz to find out what they need to pass the quiz. Randomizing question order on quizzes and exams, plus randomizing answer orders, will help reduce cheating between students, and most LMS offer these features.

Plagiarism remains a concern for many faculty members who are reluctant to embrace online teaching, but tools to detect plagiarism have significantly improved the

\footnotetext{
${ }^{27}$ Admittedly, a few institutions have developed proctored testing centers where students can take online exams, but to my way of thinking a class would not be a truly "online" course if there was an on-campus component.
}

\footnotetext{
${ }^{28}$ See for example Jeremy B. Williams and Amy Wong, "The Efficacy of Final Examinations: A Comparative Study of Closed-Book, Invigilated Exams and Open-Book, Open-Web Exams," British Journal of Educational Technology, 40:2 (2009), 227-236.
} ${ }^{29}$ Joan Conkin and Neddie Serra, "Continuing Education Corner: Multiple Choice Testing," New Jersey
Nurse, 27 (1997), 7.

${ }^{30}$ Thomas Brothen and Catherine Wambach, "The Value of Time Limits on Internet Quizzes," Teaching of Psychology, 3 1:1 (2004), 64. 
last few years. Turnitin, which is built into Canvas Instructure, and the Blackboard SafeAssign system work quite well in identifying plagiarism on submitted papers. However, while anti-plagiarism software is useful, there are more proactive strategies in dealing with academic dishonesty.

One key to reducing or even eliminating plagiarism is simply to design difficultto-plagiarize writing assignments. One strategy is to use a version of the aforementioned first-person fictional narrative paper illustrated in the section on discussion forums. Below is an example of an assignment prompt designed in lieu of having the students write a traditional book review of the classic microhistory book The Return of Martin Guerre by Natalie Zemon Davis:

After reading The Return of Martin Guerre, imagine that you are a villager in the town of Artigat during the time covered in this narrative; your character might be a poor peasant, a merchant, an artisan, or a person of higher socioeconomic status. Compose a narrative in which you create a fictional historical character, making sure to include biographical details for your fictional character. Discuss your history and life in the village, and discuss how you became acquainted with Arnaud du Tilh/Martin Guerre. Considering the evidence presented in the text, discuss why your character is inclined to believe or disbelieve the claims of du Tilh, making sure to include the interactions your character experienced with the main characters of the story. Discuss your character's assessment of the legal findings, and whether your character believes that justice was served in the case. Stronger papers will exhibit evidence that the student understands the major themes and events developed by Natalie Zemon Davis in The Return of Martin Guerre. ${ }^{31}$

Academic dishonesty and plagiarism should be addressed in the "Start Here" pages and in the course syllabus and these sections should list the types of behaviors that constitute plagiarism. I include reminders about plagiarism policies on all assignment prompts, and post announcements discouraging the behavior as well as links to informative Web pages and videos on plagiarism to defuse the "I didn't know I was plagiarizing" argument.

Finally, instructors should be transparent with students regarding the use of antiplagiarism software in online courses. Turnitin can be embedded directly into the course shell on Canvas, and the course website shares the Turnitin report with students as soon as it is available. Most students will not consider plagiarism to be worth their time when they know that an instructor is closely monitoring their written work.

${ }^{31}$ Brooks, 2013. 


\section{Conclusion}

Teaching history in online settings requires different philosophical approaches and skill sets than in traditional F2F classrooms. Online history instructors need to develop the ability to problem-solve site design and student access problems that inevitably occur, and possessing the ability to see the course shell through the eyes of a student is also a valuable skill. Assignments should be designed with the knowledge that online students have access to resources that F2F students lack, especially as related to quizzes and exams.

In some ways teaching online is more labor-intensive than many F2F classes, given the fact that written work is the principal means by which online students demonstrate mastery of course content and themes. Increasingly faculty job postings include online teaching experience as a requirement for open positions, and as universities and colleges continue to pursue online education, the ability to teach online is directly related to career success in higher education.

\section{Bibliography}

Barnett-Queen, Timothy, Blair, Robert, and Merrick, Melissa. "Student Perspectives of Online Discussions: Strengths and Weaknesses." Journal of Technology in Human Services, 23:3-4 (2005), 229-244.

Brooks, Michael E. "Converting a Narrated PowerPoint into a WMV Video." Accessed August 13, 2013, from https://www.youtube.com/watch?v= IRA2cH7izU4.

Brothen, Thomas and Wambach, Catherine. "The Value of Time Limits on Internet Quizzes." Teaching of Psychology, 31:1 (2004), 62-64.

Clarke, Sandra. "Peer Interaction and Engagement Through Online Discussion Forums: A Cautionary Tale." Liverpool Law Review, 32 (2011), 149-163.

Cochran, Justin D., et al. "The Role of Student Characteristics in Predicting Retention in Online Courses." Research in Higher Education, 55:1 (2014), 27-48.

Conkin, Joan, and Serra, Neddie. "Continuing Education Corner: Multiple Choice Testing." New Jersey Nurse, 27 (1997), 6-9.

Dennen, Vanessa Paz. "From Message Posting to Learning Dialogues: Factors Affecting Learner Participation in Asynchronous Discussion." Distance Education, 26:1 (2005), 127-148.

. "Presence and Positioning as Components of Online Instructor Persona." Journal of Research on Technology in Education, 40:1 (2007), 95-108.

Dow, Myrna T. "Implications of Social Presence for Online Learning: A Case Study of MLS Students." Journal of Education for Library and Information Science, 49:4 (Fall 2008), 231--242. 
Land, Susan, and Dornisch, Michele. "A Case Study of Student Use of Asynchronous Bulletin Board Systems (BBS) to Support Reflection and Evaluation." Journal of Educational Technology Systems, 30:4 (2002), 365-377.

Mechur Karp, Melinda. "Tech Alone Won't Cut It," Inside Higher Ed, 13 January 2014, http://www.insidehighered.com/views/2014/01/13/essay-looks-how-earlywarning-systems-can-better-boost-retention.

Moore, Janet C., Sener, John, and Fetzner, Marie. "Getting Better: ALN and Student Success." Journal of Asynchronous Learning Networks, 13:3 (2009), 85-114.

Rovait, Alfred P., and Wighting, Mervyn J. "Feelings of Alienation and Community among Higher Education Students in a Virtual Classroom." Internet and Higher Education, 8 (2005), 97-110.

Whatley, Janet, and Ahmad, Amrey. "Using Video to Record Summary Lectures to Aid Students' Revision." Interdisciplinary Journal of Knowledge and Learning Objects, 3 (2007), 114-196.

Williams, Jeremy B., and Wong, Amy. "The Efficacy of Final Examinations: A Comparative Study of Closed-Book, Invigilated Exams and Open-Book, OpenWeb Exams." British Journal of Educational Technology, 40:2 (2009), 227-236.

University of Central Florida. "Research Initiative for Teaching Effectiveness: Faculty Perceptions of Teaching on the Web." Accessed August 13, 2013, from http://pegasus.cc.ucf.edu/ rite/impactevaluation.htm\#Success. 